\title{
Doses de boro e água residuária na produção do girassol ${ }^{1}$
}

\author{
Levels of boron and wastewater in production of sunflower
}

\author{
José Amilton Santos Junior ${ }^{2 *}$, Hans Raj Gheyi ${ }^{3}$, Nildo da Silva Dias ${ }^{4}$, Frederico Antônio Loureiro Soares ${ }^{5}$ e \\ Reginaldo Gomes Nobre ${ }^{6}$
}

\begin{abstract}
Resumo - A disponibilidade hídrica de qualidade tem se tornado em todo o mundo, um dos principais entraves à expansão das fronteiras agrícolas. Dentro deste contexto o presente trabalho teve como objetivo avaliar os efeitos de doses de boro e da irrigação com dois tipos de água, residuária e de abastecimento, nos componentes de produção do girassol (Helianthus annuus L.) cv. EMBRAPA 122/V-2000. A pesquisa foi realizada em ambiente protegido da Universidade Federal de Campina Grande, em delineamento em blocos casualizados, analisados em esquema fatorial 5 x 2 sendo cinco doses de boro (0 - testemunha; 1,$0 ; 2,0 ; 3,0$ e 4,0 $\mathrm{mg} \mathrm{L}^{-1}$ ) combinados com dois tipos de água de irrigação ( $\mathrm{R}$ - residuária e $\mathrm{AB}$ - abastecimento), com três repetições. A análise estatística compreendeu análises de variância (teste F) e as médias foram comparadas pelo teste de Tukey para comparar os fatores qualitativos em 0,05 de probabilidade. Verificou-se que as doses de boro e tipos de água utilizados não influenciaram nenhuma variável ligada à produção de aquênios; no entanto, a irrigação com água residuária influenciou positivamente as variáveis fitomassa fresca e seca das folhas, do caule e da parte aérea, todas ligadas à produção de forragem.
\end{abstract}

Palavras-chave - Disponibilidade hídrica. Reúso de água. Helianthus annuus - Produtividade. Aquênios.

\begin{abstract}
The availability of water of quality has become worldwide, a major constraint to expanding agricultural frontiers. Within this context, this study aimed to evaluate the effects of boron doses and irrigation with two types of water, wastewater and municipal supply water, on yield components of sunflower (Helianthus annuus L.) cv. EMBRAPA 122/V-2000. The study was conducted in a greenhouse at the Federal University of Campina Grande, in a randomized block design, analyzed in a $5 \mathrm{x} 2$ factorial with five $\mathrm{B}$ of boron $\left(0 ; 1.0 ; 2.0 ; 3.0\right.$ and $\left.4.0 \mathrm{mg} \mathrm{L}^{-1}\right)$ combined with two types of irrigation water ( $\mathrm{R}$ - wastewater and AB - municipal supply water) with three replications. Statistical analysis consisted of analysis of variance (F test) and means were compared by Tukey test to compare qualitative factors at 0.05 probability. It was found that the boron levels and types of water did not affect any varieble related to production of seeds, however, irrigation with wastewater variables positively influenced the fresh and dry leaves, stem and shoot all related to forage production.
\end{abstract}

Key words - Water availability. Water reuse. Helianthus annuus - Productivity. Achenes.

\footnotetext{
* Autor para correspondência

${ }^{1}$ Recebido para publicação em 22/09/2010; aprovado em 26/03/2011

Trabalho extraído da Dissertação de Mestrado do primeiro autor apresentada a coordenação de pós-graduação em Engenharia Agrícola da UFCG

${ }^{2}$ Programa de Pós-Graduação em Engenharia Agrícola, UAEA/UFCG, Av. Aprigio Velloso, 882, Bairro Universitário, Bloco CM, Caixa Postal

10.087, Campina Grande-PB, Brasil, 58.429-140, eng.amiltonjr@hotmail.com

${ }^{3}$ Universidade Federal do Recôncavo da Bahia, Cruz das Almas-BA, Brasil, hans@deag.ufcg.edu.br

${ }^{4}$ Departamento de Ciências Ambientais e Tecnológicas/UFERSA, Mossoró-RN, Brasil, nildo@ufersa.edu.br

${ }^{5}$ Instituto Federal de Educação, Ciência e Tecnologia de Goiás, Goiânia-GO, Brasil, fredalsoares@hotmail.com

${ }^{6}$ UAGRA, Universidade Federal de Campina Grande, Pombal-PB, Brasil, rgomesnobre@yahoo.com.br
} 


\section{Introdução}

O girassol é uma dicotiledônea anual adaptada a diversas condições edafoclimáticas sendo cultivada em todos os continentes com grande importância na economia mundial, destacando-se na produção de matéria-prima, farelo e óleo, em relação a outras oleaginosas como soja, colza, algodão e amendoim. Os maiores produtores de grãos são a Rússia, Ucrânia, União Européia e Argentina (FAGUNDES et al., 2007).

O girassol também é indicado como boa alternativa no sistema de rotação e sucessão de cultivo sendo excelente recicladora de nutrientes - já que possui um sistema radicular axial profundo que disponibiliza grande parte do fósforo e potássio para a cultura sucessora - e promotora de colonização micorrízica, proporcionando ganhos expressivos de produtividade nas culturas que lhe seguem: soja após girassol teve aumento de $15 \%$, e milho após girassol teve aumento de 30\% (MORGADO et al., 2002).

Para Oliveira et al. (2003), apesar de ter sido introduzido no Brasil como oleaginosa, a cultura do girassol tem sido estudada também como forrageira alternativa. Muzubuti et al. (2002) compararam silagem de sorgo, de milho e de girassol e, concluíram que as silagens de milho e de girassol foram qualitativamente superiores às de sorgo; sua silagem é de elevado valor nutritivo $(30 \%$ de matéria seca, $11,7 \%$ de proteína bruta e 4993 kcal de energia bruta) além de ser bem aceita pelos animais.

Não obstante, nas regiões áridas e semiáridas, a água se tornou um fator limitante para o desenvolvimento urbano, industrial e agropecuário. Planejadores e entidades gestoras de recursos hídricos procuram, continuadamente, novas fontes de recursos para complementar a disponibilidade hídrica existente. Em todo o mundo, tem-se aumentado a necessidade de se utilizar águas de qualidade inferior na agricultura, o que torna o uso de águas residuárias uma fonte hídrica para a expansão das áreas irrigadas. Assim, a técnica de reúso tende a ser um eficiente instrumento para a gestão dos recursos hídricos no Brasil e no mundo nos próximos anos (NOBRE et al., 2008).

$\mathrm{O}$ incremento de nutrientes pelas águas residuárias e a relação entre a produção de girassol e a adubação com nitrogênio, fósforo e potássio, já foi avaliada por Miller et al. (2004). No entanto, Ungaro (1990) mostrou que a cultura do girassol é sensível à deficiência de boro, a qual resulta na inibição do crescimento da cultura. Por outro lado, a toxicidade desse micronutriente também limita o crescimento, o rendimento e a qualidade das sementes.
O boro exerce papel importante no processo de florescimento e na formação da semente. Dentre as funções desempenhadas pelo boro se destaca a participação na formação das paredes celulares, na germinação do pólen, na divisão celular, no florescimento e na frutificação, fato que reafirma a necessidade de estudos direcionados as exigências de boro pela cultura do girassol (FAGERIA et al., 2002).

Neste sentido, a sensibilidade do girassol em relação ao boro ainda carece de estudos quantitativos e qualitativos no sentido de evitar a deficiência e a toxicidade, favorecendo o desenvolvimento da cultura em níveis de máximo potencial genético.

Assim, objetivou-se com este trabalho avaliar os componentes de produção da cultura do girassol relacionados à produção de aquênios destinados à extração do óleo, e relacionados à produção de fitomassa visando o incremento da forragem para alimentação animal - quando submetida a doses crescentes de boro e irrigada com água residuária oriunda de esgoto doméstico.

\section{Material e métodos}

O experimento foi conduzido em condições de casa de vegetação durante o período de abril a julho de 2009, na Unidade Acadêmica de Engenharia Agrícola, do Centro de Tecnologia e Recursos Naturais (CTRN) da Universidade Federal de Campina Grande (UFCG), Campina Grande - PB (7²12 52' de latitude Sul, 3554'24” de longitude Oeste e altitude média de $550 \mathrm{~m}$ ).

Os dados de temperatura e umidade relativa do ar no interior da casa de vegetação foram medidos por uma mini estação $\mathrm{HOBO}^{\circledR}$ Temperature Data Logger modelo U12, em que foi registrado a cada $3 \mathrm{~h}$, sendo os dados médios mensais apresentados na Tabela 1 . Os valores relativos à temperatura e umidade relativa do ar foram satisfatórios, dentro da faixa exigida pela cultura, não resultando estresse às plantas.

A variedade estudada foi a EMBRAPA 122/V2000, cujas sementes foram fornecidas pela EMBRAPA Soja, escritório de Dourados - MS. As mudas provenientes de tubetes de PVC foram transplantadas para vasos de polietileno com capacidade volumétrica de $6 \mathrm{~L}$, aos 25 dias após o semeio (DAS).

O delineamento experimental utilizado foi em blocos casualizados, em esquema fatorial 5 × 2 , com cinco doses de boro ( 0 - testemunha, 1,0;2,0;3,0 e 4,0 ppm) e dois tipos de água de irrigação (água residuária oriunda de esgoto doméstico - $\mathrm{R}$ e água de abastecimento - AB), com três repetições; totalizando 
Tabela 1 - Médias mensais de temperatura e umidade relativa do ar dentro da casa de vegetação observados no período de estudo

\begin{tabular}{ccc}
\hline Mês & Temperatura $\left({ }^{\circ} \mathrm{C}\right)$ & Umidade Relativa $(\%)$ \\
\hline Abril & 26,82 & 75,18 \\
Maio & 25,74 & 78,76 \\
Junho & 24,54 & 78,12 \\
Julho & 24,87 & 76,14 \\
\hline
\end{tabular}

30 unidades experimentais. Como fonte de B foi utilizado o ácido bórico aplicado em fundação.

A água residuária utilizada foi proveniente de um córrego que passa ao lado da área experimental, oriunda de bairros próximos ao Campus I da UFCG, captada por meio de um conjunto motor bomba e armazenada em um tonel de PVC (capacidade de 200 L); no ponto de captação, a água foi submetida a filtração (tela + areia) durante o bombeamento. As águas (abastecimento e residuária) usadas no experimento foram analisadas quanto à qualidade química no Laboratório de Irrigação e Salinidade (LIS) da UFCG, seguindo as metodologias propostas pela EMBRAPA (1997), cujos resultados encontram-se na Tabela 2.

A irrigação utilizando os dois tipos de água foi realizada do semeio até 25 dias após a semeadura (DAS), aplicando-se um volume fixo de $10 \mathrm{~mL}$ por tubete duas vezes ao dia, todos os dias; após o transplantio a irrigação foi realizada buscando a manutenção do solo à capacidade de campo, aplicando-se diariamente, o valor consumido (volume aplicado - volume drenado) $+5 \%$ de fração de lixiviação. Na fase de maturação fisiológica a irrigação foi suspensa oito dias antes da colheita.

O solo utilizado foi o Neossolo Regolítico tipo franco-arenoso, não salino e não sódico cujas características físicas e químicas estão apresentadas na Tabela 3. Estas análises foram realizadas antes do início do experimento no Laboratório de Irrigação e Salinidade da UFCG, segundo metodologia descrita pela EMBRAPA (1997). A coleta do solo foi realizada na camada superficial (0$20 \mathrm{~cm}$ ) nas imediações do distrito de São José da Mata, localizado no município de Campina Grande, PB, o qual foi seco ao ar, destorroado, homogenizado e peneirado, para então ser acondicionado nos vasos, os quais tinham a sua base perfurada e foram preenchidos com $200 \mathrm{~g}$ de brita $\mathrm{n}^{\mathrm{o}} 1$, mais $8 \mathrm{~kg}$ de solo.

As adubações químicas foram realizadas em todos os vasos em fundação, seguindo recomendação proposta por Novais et al. (1991), utilizando-se as dosagens de $300 ; 100 ; 150$ e $40 \mathrm{mg} \mathrm{kg}^{-1}$ de solo de $\mathrm{P}_{2} \mathrm{O}_{5}, \mathrm{~N}, \mathrm{~K}_{2} \mathrm{O}$ e $\mathrm{S}$, respectivamente.

Os componentes de produção foram avaliados por ocasião da colheita das plantas, quando as mesmas se encontravam no estágio de maturação fisiológica (R9), segundo metodologia proposta por Schneiter e Miller (1981): a) variáveis ligadas à produção de aquênios: fitomassa fresca dos aquênios - FA; número de aquênios viáveis - NAV; números de aquênios não viáveis - NANV; porcentagem de aquênios não viáveis - \%ANV; diâmetro interno do capitulo - DCap; b) variáveis relacionadas à produção de forragem: fitomassa fresca e seca da parte aérea - FFPA e FSPA; fitomassa fresca e seca das raízes - FFR e FSR; fitomassa fresca e seca do caule - FFCaule e FSCaule; fitomassa fresca e seca das folhas - FFF e FSF; número de folhas - NF; diâmetro caulinar - DCaule; e comprimento de raiz - CR. Além destas, foi feita a contagem do número de dias transcorridos do plantio a colheita - TPC.

$\mathrm{O}$ material vegetal foi coletado e acondicionado em estufa de ventilação forçada a $65^{\circ} \mathrm{C}$ até atingir peso constante. Após este período foi realizada a determinação das fitomassas. Os aquênios viáveis e não viáveis foram contados manualmente sendo separados utilizando o critério do peso, cor, sanidade e tamanho.

O diâmetro do caule foi medido a $5 \mathrm{~cm}$ da superfície do solo utilizando um paquímetro digital. $\mathrm{Na}$ contagem do número de folhas, considerou-se apenas as folhas maiores que $3 \mathrm{~cm}$, sadias e com coloração verde (fotossinteticamente ativas). O comprimento da raiz foi mensurado após lavagem destas, utilizando régua milimetrada.

Os dados obtidos foram submetidos à análise de variância e as médias dos valores qualitativos foram

Tabela 2 - Caracterização química da água residuária $(\mathrm{R})$ e de abastecimento $(\mathrm{AB})$ utilizada na irrigação

\begin{tabular}{|c|c|c|c|c|c|c|c|c|c|c|c|c|c|}
\hline \multirow{2}{*}{ Água } & \multirow{2}{*}{$\mathrm{pH}$} & \multirow{2}{*}{$\mathrm{CE}\left(\mathrm{dS} \mathrm{m}^{-1}\right)$} & $\mathrm{P}$ & $\mathrm{K}$ & $\mathrm{N}$ & $\mathrm{Na}$ & $\mathrm{Ca}$ & $\mathrm{Mg}$ & $\mathrm{Zn}$ & $\mathrm{Cu}$ & $\mathrm{Fe}$ & $\mathrm{Mn}$ & \multirow{2}{*}{$\begin{array}{c}\text { RAS } \\
\left(\mathrm{mmol} \mathrm{L}^{-1}\right)^{0,5}\end{array}$} \\
\hline & & & \multicolumn{10}{|c|}{$\mathrm{mg} \mathrm{L}^{-1}$} & \\
\hline $\mathrm{R}$ & 7,45 & 1,84 & 3,59 & 31,6 & 28,6 & 147,6 & 81,2 & 39,5 & 0,01 & 0,08 & 0,001 & 0,02 & 3,36 \\
\hline $\mathrm{AB}$ & 7,5 & 0,38 & nd & 5,47 & nd & 35,6 & 20,0 & 15,8 & nd & nd & nd & nd & 1,45 \\
\hline
\end{tabular}

nd - não determinado 
comparadas pelo teste de Tukey ao nível de 5\% de significância. Realizaram-se todas as análises através do programa estatístico SISVAR-ESAL (FERREIRA, 2000).

Tabela 3 - Características físicas e químicas do material de solo utilizado no experimento

\begin{tabular}{|c|c|c|}
\hline Característica & Unidade & Valor \\
\hline Granulometria & $\%$ & \\
\hline Areia & & 82,19 \\
\hline Silte & & 12,76 \\
\hline Argila & & 5,05 \\
\hline Densidade & $\mathrm{kg} \mathrm{dm}^{-3}$ & \\
\hline Aparente & & 1,66 \\
\hline Real & & 2,81 \\
\hline Porosidade & $\%$ & 40,92 \\
\hline Complexo sortivo & $\mathrm{cmol}_{\mathrm{c}} \mathrm{kg}^{-1}$ & Valor \\
\hline Hidrogênio & $\mathrm{cmol}_{\mathrm{c}} \mathrm{kg}^{-1}$ & 1,20 \\
\hline Cálcio & $\mathrm{cmol}_{\mathrm{c}} \mathrm{kg}^{-1}$ & 1,68 \\
\hline Magnésio & $\mathrm{cmol}_{\mathrm{c}} \mathrm{kg}^{-1}$ & 1,27 \\
\hline Sódio & $\mathrm{cmol}_{\mathrm{c}} \mathrm{kg}^{-1}$ & 0,06 \\
\hline Potássio & $\mathrm{cmol}_{\mathrm{c}} \mathrm{kg}^{-1}$ & 0,07 \\
\hline Alumínio & $\mathrm{cmol}_{\mathrm{c}} \mathrm{kg}^{-1}$ & 0,0 \\
\hline $\mathrm{T}$ & $\mathrm{cmol}_{\mathrm{c}} \mathrm{kg}^{-1}$ & 4,28 \\
\hline Carbonato Cálcio Qualitativo & - & Ausente \\
\hline Carbonato Orgânico & $\mathrm{g} \mathrm{kg}^{-1}$ & 2,0 \\
\hline Matéria Orgânica & $\mathrm{g} \mathrm{kg}^{-1}$ & 3,4 \\
\hline Nitrogênio & $\mathrm{g} \mathrm{kg}^{-1}$ & 0,2 \\
\hline Fósforo assimilável & $\mathrm{mg} \mathrm{kg}^{-1}$ & 8,8 \\
\hline $\mathrm{pH} \mathrm{H} 2 \mathrm{O}$ & - & 6,12 \\
\hline CE $1: 2,5$ & $\mathrm{dS} \mathrm{m}^{-1}$ & 0,16 \\
\hline Extrato de saturação & $\operatorname{mmol}_{c} L^{-1}$ & \\
\hline Cálcio & $\operatorname{mmol}_{c} L^{-1}$ & 2,1 \\
\hline Magnésio & $\operatorname{mmol}_{\mathrm{c}} \mathrm{L}^{-1}$ & 1,9 \\
\hline Sódio & $\operatorname{mmol}_{c} L^{-1}$ & 2,0 \\
\hline Potássio & $\operatorname{mmol}_{c} L^{-1}$ & 0,2 \\
\hline Carbonato & $\operatorname{mmol}_{\mathrm{c}} \mathrm{L}^{-1}$ & 0,0 \\
\hline Bicarbonato & $\operatorname{mmol}_{c} L^{-1}$ & 2,8 \\
\hline Cloreto & $\mathrm{mmol}_{\mathrm{c}} \mathrm{L}^{-1}$ & 2,6 \\
\hline Sulfato & $\mathrm{mmol}_{\mathrm{c}} \mathrm{L}^{-1}$ & Ausente \\
\hline RAS & $\left(\mathrm{mmol}_{\mathrm{c}} \mathrm{L}^{-1}\right)^{0,5}$ & 1,42 \\
\hline pH pasta saturação & - & 5,6 \\
\hline CEes & $\mathrm{dS} \mathrm{m}^{-1}$ & 0,67 \\
\hline
\end{tabular}

\section{Resultados e discussão}

Em uma análise inicial das variáveis ligadas à produção de aquênios nota-se que os níveis de boro não afetaram significativamente as variáveis FA, NAV, NANV, $\%$ ANV, DCap e TPC (TAB. 4), discordando dos resultados obtidos por Marchetti et al. (2001) para as mesmas variáveis. Baseando-se nestes resultados, denota-se que a não significância das doses de boro faz menção à existência de boro na água residuária ou no solo em quantidades suficientes às necessidades nutricionais da cultura.

De acordo com Sandri et al. (2006) o teor de boro máximo encontrado em seus trabalhos utilizando a água residuária, foi de $0,3 \mathrm{mg} \mathrm{L}^{-1}$ sendo que o limite máximo de boro na água de irrigação, considerada de boa qualidade, isto é, da Classe 1 , é de $0,5 \mathrm{mg} \mathrm{L}^{-1}$. Concentrações de boro entre 0,5 e $1,0 \mathrm{mg} \mathrm{L}^{-1}$, podem ser encontradas em efluente doméstico, devido ao uso de componentes à base de boro, em produtos de limpeza (KIRKHAM, 1986).

De acordo com Menezes e Silva (2008) os atributos químicos de um Neossolo Regolítico $(0-20 \mathrm{~cm})$ na região de Esperança, PB, a qual dista cerca de $30 \mathrm{~km}$ de Campina Grande, PB, cidade onde foi realizada a pesquisa, apresentam, em termos de boro, aproximadamente $0,61 \mathrm{mg} \mathrm{kg}^{-1}$. Essas informações relativas à presença de boro na água residuária e no solo corroboram com os resultados encontrados, uma vez que os níveis deste micronutriente exigidos pela cultura são mínimos, e podem ser plenamente satisfeitos através da presença natural do boro no solo, ou o seu incremento através da aplicação de águas residuárias. No entanto, observou-se durante as atividades experimentais que todas as plantas apresentaram, em pequena escala, necrose e queda de folhas mais velhas, sintoma típico de toxidez por boro. A exigência em boro pelo girassol é alta quando comparado com outras espécies cultivadas, sendo pouco eficiente na absorção deste nutriente do solo, podendo ter perdas de 15 a 40\% quando cultivado em solos com baixo teor deste micronutriente (SOUZA et al., 2004). Para a correção da deficiência de boro, recomenda-se 1,0 a $2,0 \mathrm{~kg} \mathrm{ha}^{-1}$ do nutriente (CASTRO, 2006). A falta desde micronutriente na cultura ocasiona redução no crescimento e na produção de massa seca, redução no tamanho do capítulo e na massa das sementes, com redução nos conteúdos de açúcares, óleo e amido (BONACIN et al., 2008).

Ainda em relação à Tabela 4, vale ressaltar que, embora não tenha sido observado efeito significativo das doses de boro, para as variáveis TPC e FA, a dose de $3 \mathrm{mg} \mathrm{L}^{-1}$ proporcionou uma redução de 5 dias no ciclo da cultura e a dose $2 \mathrm{mg} \mathrm{L}^{-1}$ proporcionou um aumento de $9 \%$ na FA, respectivamente em comparação com a testemunha. Já a dose de $4 \mathrm{mg} \mathrm{L}^{-1}$ apresentou um decréscimo no NANV de $45,78 \%$ em comparação com a testemunha. 
Tabela 4 - Resumo da ANOVA e médias para Fitomassa dos Aquênios (FA), Número de Aquênios Viáveis (NAV), Número de Aquênios Não Viáveis (NANV), porcentagem de Aquênios Não Viáveis (\%ANV), Diâmetro do Capitulo - Dcap e o Tempo do Plantio a Colheita (TPC), para os dois tipos de águas de irrigação e doses crescentes de boro na produção do girassol - cv. EMBRAPA 122/V-2000

\begin{tabular}{|c|c|c|c|c|c|c|c|}
\hline \multirow{2}{*}{ Causa de Variação } & \multirow{2}{*}{ GL } & \multicolumn{6}{|c|}{ Quadrado médio } \\
\hline & & $\mathrm{FA}^{1}$ & $\mathrm{NAV}^{1}$ & NANV $^{1}$ & $\% \mathrm{ANV}^{2}$ & DCap & TPC \\
\hline Boro (B) & 4 & $0,22^{\mathrm{ns}}$ & $1,88^{\mathrm{ns}}$ & $15,78^{\mathrm{ns}}$ & $0,04^{\mathrm{ns}}$ & $0,12^{\mathrm{ns}}$ & $74,55^{\mathrm{ns}}$ \\
\hline Água (A) & 1 & $0,80^{\mathrm{ns}}$ & $25,01^{\mathrm{ns}}$ & $18,09^{\text {ns }}$ & $0,01^{\mathrm{ns}}$ & $0,84^{\mathrm{ns}}$ & $0,03^{\mathrm{ns}}$ \\
\hline Interação B x A & 4 & $0,38^{\mathrm{ns}}$ & $9,54^{\mathrm{ns}}$ & $32,42^{\mathrm{ns}}$ & $0,07^{\mathrm{ns}}$ & $0,22^{\mathrm{ns}}$ & $39,78^{\mathrm{ns}}$ \\
\hline Resíduo & 20 & 0,50 & 6,24 & 24,45 & 0,06 & 1,04 & 70,80 \\
\hline $\mathrm{CV}$ & & 15,97 & 16,28 & 55,76 & 50,72 & 11,81 & 8,46 \\
\hline \multirow{2}{*}{\multicolumn{2}{|c|}{ Dose de Boro $\left(\mathrm{mg} \mathrm{L}^{-1}\right)$}} & \multicolumn{6}{|c|}{ Médias } \\
\hline & & (g) & Unidade & Unidade & $(\%)$ & $(\mathrm{cm})$ & (dias) \\
\hline 0 & & 19,04 & 255,66 & 112,50 & 30,56 & 8,39 & 100,83 \\
\hline 1 & & 16,90 & 244,66 & 136,50 & 35,81 & 8,59 & 104,83 \\
\hline 2 & & 20,92 & 257,00 & 110,00 & 30,00 & 8,78 & 97,33 \\
\hline 3 & & 19,32 & 228,33 & 85,00 & 27,12 & 8,67 & 95,83 \\
\hline 4 & & 19,53 & 220,00 & 61,00 & 21,70 & 8,69 & 98,33 \\
\hline \multicolumn{8}{|l|}{ Tipo de água } \\
\hline Residuária & & 20,60 & 269,86 & 111,93 & 29,32 & 8,79 & 99,4 \\
\hline Abastecimento & & 17,69 & 212,40 & 90,06 & 29,77 & 8,46 & 99,47 \\
\hline
\end{tabular}

${ }^{*} \mathrm{e}{ }^{* *}$ significativo a 5 e $1 \%$ pelo teste $\mathrm{F}$, respectivamente. ${ }^{\mathrm{ns}}=$ não significativo a $5 \% ;{ }^{1}$ Valores transformados em função da equação $\sqrt{ }(\mathrm{X}+1)$ para análise; ${ }^{2}$ Os valores da variável \%ANV foram transformados em valores decimais de acordo com Gomes (1987) pela função (arcoseno $\sqrt{ }$ x.100)

Com relação à \%ANV no que diz respeito às doses de boro e a irrigação com águas residuárias, não houve diferenças significativas; no entanto, a dose de $4 \mathrm{mg} \mathrm{L}^{-1}$ promoveu uma redução de $29 \%$ quando comparado com a testemunha.

Braz e Rossetto (2009) analisando o cultivo do girassol cv. EMBRAPA 122/ V-2000 em um Planossolo verificaram que a produção média de aquênios por planta foi de 940 unidades, enquanto no presente estudo as doses de $1 ; 2$ e $3 \mathrm{mg} \mathrm{L}^{-1}$ apresentaram produções médias de 513; 489 e 450 unidades de aquênio, respectivamente. No entanto se comparar a massa de 1.000 aquênios estimada por Braz e Rossetto (2009) que foi de 53,66 g, os resultados foram similares aos 54,33 g encontrados no presente trabalho para a dose de $3 \mathrm{mg} \mathrm{L}^{-1}$ interagindo com a água residuária.

Lobo e Grassi Filho (2007) verificaram maior produção de aquênios de girassol nos tratamentos com águas residuárias em comparação à adubação mineral e à testemunha sem adubação, podendo ser utilizada como fonte alternativa para a substituição da adubação tradicional, sem prejuízos em termos de rendimento quando comparado à adubação mineral. Com relação ao Diâmetro do Capitulo (Dcap) Lobo e Grassi Filho (2007) verificaram que os valores foram influenciados positivamente pela utilização da água residuária em plantas de girassol.

Em relação às variáveis relacionadas à produção de forragem, FFPA, FSPA, FFCaule e FSCaule, podese observar na Tabela 5 , que não foram influenciadas significativamente pelas doses crescentes de boro, no entanto, mostraram-se efeito significativo $(\mathrm{p}<0,01)$ para irrigação utilizando as águas residuária e de abastecimento.

As fitomassas fresca e seca da raiz (FFR e FSR), não foram influenciadas pelas doses de B (TAB. 5), concordando com os resultados obtidos por Marchetti et al. (2001). Esse fato, possivelmente está atrelado ao uso da água residuária na irrigação, já que os resultados encontrados por Andrade et al. (2007), para a germinação e o crescimento do girassol (EMBRAPA 122/V-2000) irrigado com água residuária foram significativos em termos de fitomassa fresca e seca radicular, em relação às plantas irrigadas com água de abastecimento, fato que corrobora com os resultados obtidos no presente trabalho. 
Tabela 5 - Resumo da ANOVA e médias para Fitomassa Fresca e Seca da Parte Aérea (FFPA e FSPA), Fitomassa Fresca e Seca de Raíz (FFR e FSR) e do Caule (FFCaule e FSCaule) para os dois tipos de águas de irrigação e doses crescentes de boro na produção do girassol - cv. EMBRAPA 122/V-2000

\begin{tabular}{|c|c|c|c|c|c|c|c|}
\hline \multirow{2}{*}{ Causa de Variação } & \multirow{2}{*}{ GL } & \multicolumn{6}{|c|}{ Quadrado Médio } \\
\hline & & FFPA & FSPA & $\mathrm{FFR}^{1}$ & $\mathrm{FSR}^{1}$ & FFCaule & FSCaule \\
\hline Boro (B) & 4 & $863,35^{\text {ns }}$ & $0,50^{\text {ns }}$ & $2,29^{\text {ns }}$ & $1,22^{\mathrm{ns}}$ & $41,46^{\text {ns }}$ & $1,75^{\mathrm{ns}}$ \\
\hline Água (A) & 1 & $8924,46^{* *}$ & $140,53 * *$ & $4,67^{\mathrm{ns}}$ & $2,09^{\text {ns }}$ & $859,63 * *$ & $12,61 * *$ \\
\hline Inter $\mathrm{B} \times \mathrm{A}$ & 4 & $617,80^{\mathrm{ns}}$ & $6,96^{\mathrm{ns}}$ & $1,14^{\mathrm{ns}}$ & $0,59^{\text {ns }}$ & $290,34^{\text {ns }}$ & $3,13^{\text {ns }}$ \\
\hline Resíduo & 20 & 683,48 & 15,16 & 2,08 & 0,63 & 97,15 & 2,42 \\
\hline CV (\%) & & 18,72 & 17,33 & 38,12 & 33,56 & 17,35 & 14,62 \\
\hline \multirow{2}{*}{ Dose de Boro $\left(\mathrm{mg} \mathrm{L}^{-1}\right)$} & & \multicolumn{6}{|c|}{ Médias } \\
\hline & & $(\mathrm{g})$ & $(\mathrm{g})$ & $(\mathrm{g})$ & $(\mathrm{g})$ & $(\mathrm{g})$ & $(\mathrm{g})$ \\
\hline 0 & & 138,03 & 22,01 & 10,36 & 4,20 & 59,74 & 11,02 \\
\hline 1 & & 121,53 & 22,80 & 22,50 & 7,16 & 53,29 & 10,63 \\
\hline 2 & & 137,59 & 22,54 & 19,93 & 9,01 & 56,08 & 11,24 \\
\hline 3 & & 149,88 & 22,56 & 14,74 & 2,99 & 59,08 & 10,52 \\
\hline 4 & & 151,30 & 22,43 & 9,40 & 3,43 & 55,82 & 9,83 \\
\hline \multicolumn{8}{|l|}{ Tipo de Água } \\
\hline Residuária & & $156,91 \mathrm{a}$ & $24,63 a$ & 11,78 & 3,65 & $62,15 a$ & $11,29 a$ \\
\hline Abastecimento & & $122,42 b$ & $20,30 \mathrm{~b}$ & 18,99 & 7,07 & $51,45 \mathrm{~b}$ & $10,00 \mathrm{~b}$ \\
\hline
\end{tabular}

Segundo Lucas Filho et al. (2002) a maior disponibilidade de nutrientes no solo juntamente com aplicação de águas residuárias, pode levar a um melhor desenvolvimento das plantas, com maior produção de matéria seca. Esse fato foi comprovado por Nobre et al. (2008) na avaliação do vigor do girassol irrigado com águas residuárias e concorda com os valores obtidos neste trabalho, uma vez que houve incremento da FFPA, FSPA, FFCaule e FSCaule sob irrigação com água residuária, indicando o incremento na produção de fitomassa para o fornecimento aos animais.

$\mathrm{Na}$ Tabela 6 é possível observar que as variáveis Fitomassa Fresca e Seca das Folhas (FFF e FSF) e Número de Folhas (NF) apresentaram melhor desenvolvimento sob irrigação com água residuária $(\mathrm{p}<0,01)$ não obtendo, no entanto, significância estatística para os tratamentos utilizando ácido bórico. As variáveis Diâmetro do Caule (DCaule) e Comprimento da Raiz (CR) não foram afetadas por nenhum dos tratamentos aplicados.

Entretanto, a influência do uso da água residuária é bastante evidenciada se compararmos seus efeitos aos da água de abastecimento sob as variáveis que se mostraram significativas para o tipo de água na Tabela 6. Pode-se observar que os valores significativos $(\mathrm{p}<0,01)$ foram maiores em todos os casos para as plantas irrigadas com águas residuárias, indicando que na ausência de adubação mineral, os níveis de boro encontrados em um Neossolo e presentes na água residuária de esgoto doméstico conseguem suprir as necessidades nutricionais do girassol com produção rentável (MENEZES; SILVA, 2008; SANDRI et al., 2006).

Azevedo e Oliveira (2005) ressaltam a importância da utilização de águas residuárias domésticas para o fornecimento de nutrientes e aumento de produtividade das plantas. Para Bernardi (2003) o reúso de água é uma alternativa viável e vários são os benefícios provenientes de sua aplicação na agricultura, como: a possibilidade de substituição parcial de fertilizantes químicos, com diminuição do impacto ambiental, em função da redução da contaminação dos cursos d'água; as plantas podem ser beneficiadas não apenas pela água, mas, também, dentro de certos limites, pelos materiais dissolvidos no esgoto doméstico (como matéria orgânica, nitrogênio, fósforo, potássio e micronutrientes) além da economia da quantidade de água direcionada em grandes volumes para a irrigação, que representa a maior demanda de água nas regiões secas. 
Tabela 6 - Resumo da ANOVA e médias para Fitomassa Fresca e Seca das Folhas (FFF e FSF), Diâmetro do Caule (DCaule), Comprimento de Raiz (CR) e Número de Folhas (NF) para os dois tipos de águas de irrigação e doses crescentes de boro na produção do girassol - cv. EMBRAPA 122/V-2000

\begin{tabular}{|c|c|c|c|c|c|c|}
\hline \multirow{2}{*}{ Causa de Variação } & \multirow{2}{*}{ GL } & \multicolumn{5}{|c|}{ Quadrado Médio } \\
\hline & & FFF & FSF & DCaule & $\mathrm{CR}^{1}$ & $\mathrm{NF}^{1}$ \\
\hline Boro (B) & 4 & $269,12^{\text {ns }}$ & $1,11^{\mathrm{ns}}$ & $1,12^{\text {ns }}$ & $0,80^{\text {ns }}$ & $0,10^{\text {ns }}$ \\
\hline Água (A) & 1 & $1584,42 * *$ & $32,48 * *$ & $0,67^{\mathrm{ns}}$ & $1,09^{\mathrm{ns}}$ & $1,11^{* *}$ \\
\hline Interação B x A & 4 & 50,49 & $0,36^{\mathrm{ns}}$ & $3,39^{\text {ns }}$ & $0,97^{\mathrm{ns}}$ & $0,13^{\mathrm{ns}}$ \\
\hline Resíduo & 20 & 123,09 & 1,26 & 1,63 & 1,20 & 0,22 \\
\hline $\mathrm{CV}$ & & 52,59 & 20,02 & 11,85 & 22,08 & 11,68 \\
\hline \multirow{2}{*}{\multicolumn{2}{|c|}{ Dose de boro $\left(\mathrm{mg} \mathrm{L}^{-1}\right)$}} & \multicolumn{5}{|c|}{ Médias } \\
\hline & & (g) & (g) & $(\mathrm{mm})$ & $(\mathrm{cm})$ & Unidade \\
\hline 0 & & 19,31 & 5,29 & 10,81 & 25,66 & 16,50 \\
\hline 1 & & 10,47 & 6,20 & 11,52 & 25,85 & 14,83 \\
\hline 2 & & 22,98 & 5,43 & 10,41 & 22,46 & 14,16 \\
\hline 3 & & 24,87 & 5,23 & 10,61 & 21,44 & 15,50 \\
\hline 4 & & 27,84 & 5,95 & 10,57 & 28,63 & 16,33 \\
\hline \multicolumn{7}{|l|}{ Tipo de Água } \\
\hline Residuária & & $28,36 a$ & $6,66 \mathrm{a}$ & 10,63 & 22,49 & $16,93 \mathrm{a}$ \\
\hline Abastecimento & & $13,82 b$ & $4,58 \mathrm{~b}$ & 10,94 & 27,13 & $14,00 \mathrm{~b}$ \\
\hline
\end{tabular}

${ }^{*} \mathrm{e}^{* *}=$ significativo a 5 e $1 \%$ pelo teste $\mathrm{F}$, respectivamente. ${ }^{\mathrm{ns}}=$ não significativo a $5 ;{ }^{1}$ Valores transformados em função da equação $\sqrt{ }(\mathrm{X}+1)$

\section{Conclusões}

1. As variáveis fitomassa fresca e seca da parte aérea, do caule e folhas não foram afetadas pelos tratamentos com boro, no entanto, sofreram influência positiva da aplicação de águas residuárias; as demais não sofreram efeitos quanto ao tipo de água ou doses de boro;

2. As doses de boro e tipos de água utilizados não influenciaram as variáveis ligadas à produção de aquênios; no entanto, os tratamentos utilizados influenciaram positivamente as variáveis Fitomassa Fresca e Seca das Folhas, do Caule e da Parte Aérea, todas ligadas à produção de forragem.

\section{Agradecimentos}

Os autores agradecem ao Conselho Nacional de Pesquisa e Tecnologia ( $\mathrm{CNPq})$, pela concessão de bolsa aos autores.

\section{Referências}

ANDRADE, L. O. et al. Germinação e crescimento inicial de plantas de girassol (Helianthus annuus L) irrigadas com água residuária. Educação Agrícola Superior, v. 22, n. 02, p. 48-50, 2007.

AZEVEDO, L. P. de; OLIVEIRA, E. L. de. Efeitos da aplicação de efluente de tratamento de esgoto na fertilidade do solo e produtividade de pepino sob irrigação subsuperficial. Engenharia Agrícola, v. 25, n. 01, p. 253-263, 2005.

BERNARDI, C. C. Reuso da água para irrigação. $63 \mathrm{f}$. Monografia (MBA em Gestão Sustentável da Agricultura Irrigada)-Fundação Getúlio Vargas, Brasília, 2003. Disponível em: <http://www.integracao.gov.br/.../download.asp?.../reuso/ Reuso_de_agua_irrigacao.> Acesso em: 29 ago. 2009.

BONACIN, G. A. et al. Características morfofisiológicas de sementes e produção de girassol em função de boro no solo. Revista Brasileira de Engenharia Agrícola e Ambiental, v. 13, n. 02 , p. 111-116, 2008 .

BRAZ, M. R. S.; ROSSETTO, C. A. V. Estabelecimento de plântulas e desempenho de plantas em resposta ao vigor dos aquênios de girassol. Revista Ciência Rural, v. 39, n. 07, p. 1997-2003, 2009.

CASTRO, C. et al. Boro e estresse hídrico na produção do girassol. Ciências Agrotécnicas, v. 30, n. 02, p. 214-220, 2006. 
EMBRAPA - EMPRESA BRASILEIRA DE PESQUISA AGROPECUÁRIA. Centro Nacional de Pesquisa de Solos. Manual de métodos de análise de solo. 2. ed. Rio de Janeiro, 1997.

FAGERIA, N. K. et al. Micronutrients in crop production. Advances in Agronomy, v. 77, p. 185-268, 2002.

FAGUNDES, J. D. et al. Crescimento, desenvolvimento e retardamento da senescência foliar em girassol de vaso (Helianthus annuus L.): fontes e doses de nitrogênio. Ciencia Rural, v. 37, n. 04, 2007.

FERREIRA, P. V. Estatística experimental aplicada à agronomia. 2. ed. rev. e ampl. Maceió: UFAL/EDUFAL/FUNDEPES, 2000. 437 p.

HESPANHOL, I. Potencial de reuso de água no Brasil: agricultura, indústria, municípios, recarga de aqüíferos. Bahia Análise \& Dados, v. 13, n. especial, p. 411-437, 2003.

KIRKHAM, M.B. Problems of using wastewater on vegetable crops. HortScience, v. 21, n. 01, p. 24-77, 1986.

LOBO, T. F.; GRASI FILHO, H. Níveis de lodo de esgoto na produtividade do girassol. Revista Ciência Suelo Nutrição Vegetal, v. 07, n. 03, p. 16-25, 2007.

LUCAS FILHO, M. et al. Águas residuárias: alternativa de reúso na cultura de girassol (Helianthus annuus). In: SIMPÓSIO ÌTALO-BRASILEIRO DE ENGENHARIA SANITÁRIA E AMBIENTAL, 6., 2002, Vitória. Anais... Rio de Janeiro: ABES/ANDIS, 2002. v. 1. Não paginado.

MARCHETTI, M. E. et al. Resposta do girassol (Helianthus annuus L.) a fontes e níveis de boro. Acta Scientiarum, v. 23, n. 05, p. 1107-1110, 2001.

MENEZES, R. S. C.; SILVA, T. O. da. Mudanças na fertilidade de um Neossolo Regolítico após seis anos de adubação orgânica. Revista Brasileira de Engenharia Agrícola e Ambiental, v. 12, n. 03, p. 251-257, 2008.
MILLER, A. J.; CRAMER, M. D. Root nitrogen acquisition and assimilation. Plant and Soil, v. 274, n. 01, p. 3-6, 2004.

MIZUBUTI, I. Y. et al. Consumo e digestibilidade aparente das silagens de milho (Zea mays L.), sorgo (Sorghum bicolor L.) Moench) e girassol (Helianthus annuus L.). Revista Brasileira de Zootecnia, v. 31, n. 01, p. 267-272, 2002.

MORGADO, L. N. et al. Fauna de abelhas (Hymenoptera: Apoidea) nas flores de girassol Helianthus annuus L., em Lavras - MG. Ciência Agrotecnologia, v. 26, n. 06, p. 1167$1177,2002$.

NOBRE, R. G.; et al. Vigor do girassol (Helianthus annuus L.) sob diferentes qualidades de água. Educação Agrícola Superior, v. 23, n. 01, p. 58-60, 2008.

NOVAIS, R. F. et al. Ensaio em ambiente controlado. In: OLIVEIRA, A. J. et. al. Métodos de pesquisa em fertilidade do solo. Brasília: EMBRAPA - SEA, 1991. p. 189-253. (Documentos, 3).

OLIVEIRA, M. C. et al. Efeito da inclusão de bagaço de girassol na ração sobre o desempenho e rendimento de carcaça de frangos de corte. Revista Portuguesa Zootecnia, v. 10, p. 107-116, 2003.

PATHAK, A. N.; SINGH, R. S. Effect of different concentrations of boron in irrigation water on sunflower. Journal of the Indian Society of Soil Science, v. 23, p. 388-390, 1975.

SANDRI, D. et al. Teores de nutrientes na alface irrigada com água residuária aplicada por sistemas de irrigação. Engenharia Agrícola, v. 26, n. 01, p. 45-57, 2006.

SCHNEITER, A. A.; MILLER, J.F. Description of sunflower growth stages. Crop Science, v. 21, p. 901-903, 1981.

SOUZA, A. et al. O boro na cultura de girassol. Semina: Ciências Agrárias, n. 01, v. 25, p. 27-34, 2004.

UNGARO, M. R. G. Girassol (Helianthus annuus L.). Boletim Informativo do Instituto Agronômico, Campinas, v. 200, n. 05, p. 112-113, 1990. 